\title{
Spectrophotometric Studies of N-Benzylideneaniline Ligand and its Nickel Complex
}

\author{
Emmanuel I. Chiedu ${ }^{1 *}$, Olubamike A. Adeyoju ${ }^{1}$, Faith O. Oyibo ${ }^{2}$, Godfrey O. Asieba ${ }^{1}$, Iyayi \\ Osa-Iguehide $^{2}$ \\ ${ }^{1}$ Department of Production, Analytical and Laboratory Management, Federal Institute of Industrial Research \\ Oshodi, Lagos State, Nigeria. \\ ${ }^{2}$ Environmental Analytical Research Laboratory, Department of Chemistry, University of Benin, Benin City. \\ *Corresponding Author: Emmanuel I. Chiedu, Department of Production, Analytical and Laboratory \\ Management, Federal Institute of Industrial Research Oshodi, Lagos State, Nigeria.
}

\begin{abstract}
Spectrophotometry is based on the measurement of the absorbance for monochromatic light passing through the solution containing the substance to be determined. Spectrophotometric methods can particularly be used for studying complexation equilibria and determination of the number of complexforming constituents as it is suited to the selective determination of very small concentrations of species without changing the composition of the solution. Schiff base ligand was synthesized using benzaldehyde and aniline to form a metal complex with the target analyte $\left(\mathrm{Ni}^{2+}\right)$. The melting point and electrical conductivity of the synthesized nickel complex were $175.6^{\circ} \mathrm{C}$ and $84 \times 10^{-6} \Omega^{-1} \mathrm{~cm}^{-1}$ respectively and the maximum absorbance at $360 \mathrm{~nm}$ was 0.60 . The complex was characterized using different spectroscopic techniques. The peak in FT-IR spectra at $1625.2 \mathrm{~cm}^{-1}$ confirmed the $(C=N)$ stretching vibration. The ${ }^{13} \mathrm{C}$ and ${ }^{1} \mathrm{H} N \mathrm{NR}$ spectra showed 193.8 and $10.0 \mathrm{ppm}$ respectively of $(\mathrm{CH}=\mathrm{N})$ which was assigned to the azomethine carbon atom and reveals a plausible structure of the complex.
\end{abstract}

Keywords: Absorbance, Spectroscopy, Complex, Stretching vibration.

\section{INTRODUCTION}

The degree of selectivity of a method is dependent on the complexity of the material or the sample being analyzed. In many cases the simultaneous determination of two or more metal ions enhances the selectivity of the method to a greater extent. Simultaneous spectrophotometric analysis eliminates wavelength independent matrix system effect as well as the analysis of two or more component systems. It also saves the sample, time and thereby enhances the speed of analysis[1, 2, 3]. In absorption spectroscopy, absorption measurements based upon ultraviolet light and visible radiation find application for the detection and quantitative determination of an absorbing species. Spectrophotometry is one such technique noted for its remarkable sensitivity and precision. A change in the intensity of the colour of the system with change in concentration of the system is termed as colorimetry [4]. A substance appears colored whenever it transmits or absorbs a part of a visible radiation. Absorption spectrum constitutes the optical activity of the substance. When a normal electronic structure of the substance is deformed there is either the production of the color (or) change of the color, thus when molecules containing one or more chromophores and auxochromes are subjected to irradiation, they undergo variation in electronic energy. The presence of chromophores and auxochromes in organic molecules causes deepening of color by displacing the absorption maximum towards lower wavelengths [5].

In spectrophotometric technique, when an absorbing medium is placed between the sources of a radiation, the spectroscope and the light absorbed are measured $[6,7]$. The plot of light absorbed on ordinates versus wavelength is a characteristic for an absorbing component, and forms the basis for qualitative analysis. The height of the ordinate in the plot due to the component under investigation at any particular wavelength is a measure of the concentration of the component and is thus useful for quantitative work $[5,8]$. The composition and structure of the metal chelates can be determined by various physical, chemical and spectral characteristics $[9,10]$. The change in colour of solution is an indication of complex formation. Coordinate complex contains coordinate linkages and they are less 
soluble in aqueous solutions and are more soluble in non-polar solvents. This decrease in the solubility of the compound in polar solvents indicates complex formation. Generally, ligands are weak acids or bases and the change in $\mathrm{pH}$ value is an indication of complex ion formation [11,12]. The absorption of light in the visible region by a metal ion depends on electron transitions within the ion and also upon ligand to metal bonding. Thus, the metal ion containing $\mathrm{d}$ electrons give variable colours depending on the nature of the ligand attached with the metal ion. Polarography is a powerful tool in the study of complex compounds [13, 14, 15]. This study focuses on synthesis of Schiff base ligand from benzaldehyde and aniline followed by synthesis of nickel (Ni) complex using the ligand as a complexing agent.

Characterization of the synthesized ligand and its Ni complex using melting point determination, electrical conductivity, nuclear magnetic resonance (NMR) and Infrared (IR) spectroscopic techniques.

\section{Materials AND Methods}

\subsection{Materials}

Agilent Technology FT-IR Spectrophotometer, Jenway 3020 pH meter, AR 2130 Ohaus Coporation analytical balance, Brucker Advance Neo III (400 Hz) Nuclear Magnetic Resonance (NMR) Spectrophotometer, Magnetic stirrer, Stuart heat-stir hot plate SD162, Volumetric (calibrated) flasks, beakers and conical flasks. All reagents used were of analytical grade: $\mathrm{HCl}, \mathrm{NiCl}_{2} \cdot 6 \mathrm{H}_{2} \mathrm{O}, \mathrm{HNO}_{3}, \mathrm{NaOH}$, DMSO, aniline, methylamine, benzaldehyde, 95\% ethanol, petroleum ether, methanol and distilled water.

\subsection{Methods}

\subsubsection{Preparation of $\mathrm{N}$-benzilideneaniline Ligand}

Equimolar quantity of benzaldehyde $10.143 \mathrm{ml}(1.025 \mathrm{mmol})$ and aniline $9.099 \mathrm{ml}(1.010 \mathrm{mmol})$ were mixed with rapid stirring in a $250 \mathrm{ml}$ round bottom flask provided with a stirring bar, thermometer and reflux condenser for 2 minutes. The reaction began after five seconds followed by evolution of heat and separation of water. The mixture was allowed to reflux at $800 \mathrm{C}$ for four hours and then poured with fast stirring into a $600 \mathrm{ml}$ beaker containing $16.5 \mathrm{ml}$ absolute ethanol. Crystallization of the product was achieved by allowing the mixture to further stand in

an ice bath for 30 minutes. An off-white colored solid mass of the product, N-benzilideneaniline was quantitatively transferred to a filter paper and allowed to dry in a desiccator using activated silica gel for 48 hours. $83.986 \%$ product yield was obtained and the melting point was found to be 56.20C.

\subsubsection{Synthesis of Metal Complex}

The nickel metal complex of N-benzilideneaniline ligand was prepared by dissolving $2.377 \mathrm{~g}$ of 0.01 mole of $\mathrm{NiCl}_{2} .6 \mathrm{H}_{2} \mathrm{O}$ in $5 \mathrm{ml}$ dry methanol in a $100 \mathrm{ml}$ round bottom flask. $3.625 \mathrm{~g}$ of 0.02 mole of the synthesized N-benzilideneaniline ligand was dissolved in $10 \mathrm{ml}$ of methanol in a separate $100 \mathrm{ml}$ round bottom flask. The methanolic solution of the metal chloride and the ligand were mixed and refluxed in a $250 \mathrm{ml}$ round bottom flask provided with a magnetic stirrer, thermometer and reflux condenser. Refluxing was continued for six hours at $800 \mathrm{C}$ under constant stirring. Finally, the solution was allowed to cool for 24 hours and $10 \mathrm{ml}$ of ethanol was added. An olive green colored complex was separated out, filtered, washed with petroleum ether and dried under desiccator using activated silica gel. The purity of the complex was checked by thin layer chromatography (TLC).

\section{RESULTS AND DISCUSSION}

\subsection{Physico-Chemical Characterization of N-Benzylideneaniline Metal Complex}

The complex was air-stable with high melting point and was soluble in methanol, chloroform, diethylether, ethanol and dimethylsulphoxide (DMSO). Table 3.1 summarizes the physical characteristics of the N-benzylideneaniline nickel complex.

Table3.1. Physico-chemical Characterization of $\mathrm{N}$-benzylideneaniline Nickel Complex $\left(\left[\mathrm{Ni}(\mathrm{SB})_{2}\left(\mathrm{H}_{2} \mathrm{O}\right)_{2}\right] \mathrm{Cl}_{2} .4 \mathrm{H}_{2} \mathrm{O}\right)$

\begin{tabular}{|c|c|c|c|c|c|}
\hline Variables & Colour & Melting point & IR $(\mathrm{C}=\mathrm{N})$ & ${ }^{1} \mathrm{CNMR}(\mathrm{CH}=\mathrm{N})$ & ${ }^{1} \mathrm{H}(\mathrm{CH}=\mathrm{N})$ \\
\hline Literature Value & Olive green & $176.1^{0} \mathrm{C}$ & 1627.0 & 194.0 & 9.9 \\
\hline Experimental Value & Olive green & $175.6^{0} \mathrm{C}$ & 1625.2 & 193.8 & 10.0 \\
\hline
\end{tabular}




\subsection{Measurement of Electrical Conductivity}

The electrical conductance measurement was done to ascertain whether the anions of the metal complex remain inside or outside the coordination sphere of the central metal atom. The specific conductance of the synthesized $\mathrm{Ni}^{2+}$ complex $\left(\mathrm{Ni}^{2+}=26.87^{\prime} \Omega^{-1}\right)$ was $84 \times 10^{-6} \Omega^{-1} \mathrm{~cm}^{-1}$. The conductance of $0.2 \mathrm{M} \mathrm{KCl}$ used was $849 \Omega^{-1}$. This was used to calculate the cell constant which gave $2.9 \times 10^{-6} \mathrm{~cm}^{-1}$. The high value of the molar conductance suggests that the complex behaves like an electrolyte.

\subsection{FT-IR Spectra}

The infra-red (IR) spectra of the N-benzylidene aniline (Schiff base) ligand shown in Figure 3.1a shows stretching and out-of-plane bending vibration for $\left(\mathrm{sp}^{2}=\mathrm{C}-\mathrm{H}\right)$ at 3059.50 and $689.92 \mathrm{~cm}^{-1}$ respectively. This indicates the presence of aromatic ring in the Schiff base ligand. This extremely intense absorption of out-of-plane $\mathrm{C}-\mathrm{H}$ bending vibration resulting from strong coupling with adjacent hydrogen atom, explains the presence of monosubstituted alkyl (methyl group) attached to the aromatic ring (Ar-CH). The methyl hydrogen furnishes only one weak C-H stretching at $2889.4 \mathrm{~cm}^{-1}$. The N-benzylidene free ligand also shows stretching vibration of the azomethine nitrogen with the aromatic ring at $1191.22 \mathrm{~cm}^{-}$ ${ }^{1}(\mathrm{Ar}-\mathrm{N})$ in the spectrum. The IR spectra of the complex show the coordination sites that may be involved in the chelation (Figure 3.1b). There were some guide peaks in the spectra of the ligand which were helpful in achieving the result. The position and/or the intensities of the peaks were expected to change upon chelation.

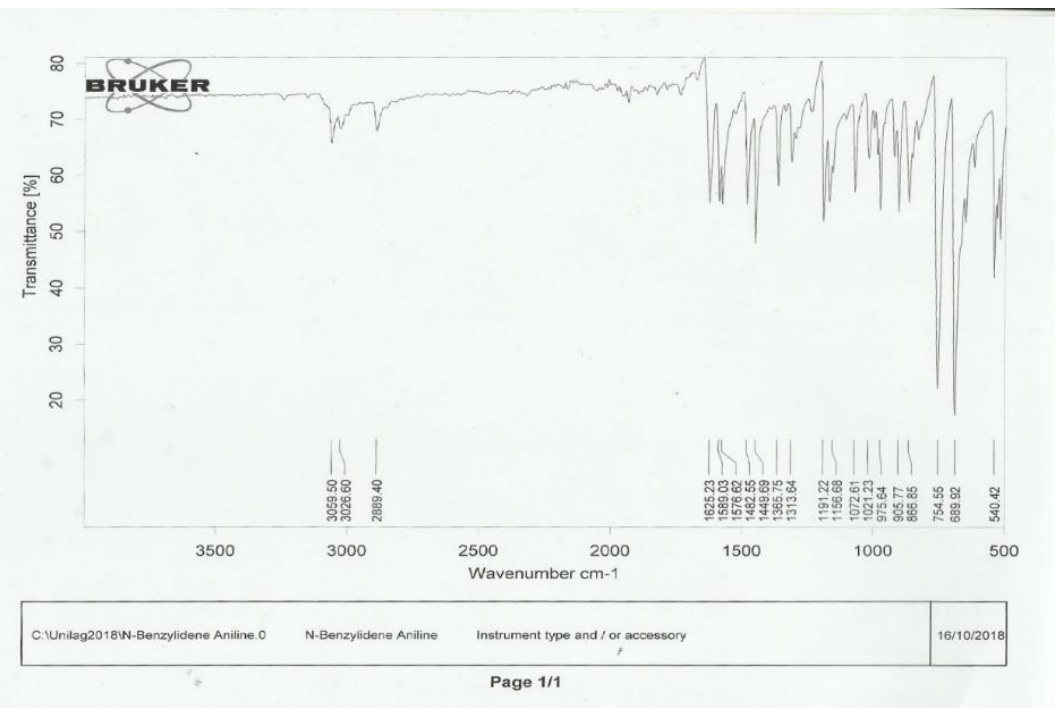

Figure3.1a. FT-IR Spectra and Mode of Vibrational Frequencies of Schiff Base



Figure3.1b. FT-IR Spectra and Mode of Vibrational Frequencies of Schiff Base-Nickel Complex 


\subsection{Nuclear Magnetic Resonance (NMR) Spectroscopy of Schiff Base-Nickel Complex}

Nuclear magnetic resonance spectroscopy was conducted to determine the plausible structure of Nbenzylideneaniline nickel complex.

\subsubsection{Proton $\left({ }^{1} H\right) N M R$}

The Schiff base (SB) proton NMR in Figure 3.4a shows highly de-shielded singlet absorption at $ð$ $(10.0183 \mathrm{ppm} 1 \mathrm{H})$ which can be attributed to the azomethine proton $(\mathrm{HC}=\mathrm{N}-)$. The region of $ð(6.4941$ - $8.6123 \mathrm{ppm}, 10 \mathrm{H}$ ) with multiple signal absorption were assigned to chemically nonequivalent aromatic protons $($ Ar-H). The strong signal which appeared at $\partial 3.3389 \mathrm{ppm}$ can be attributed to unreacted or excess droplets of phenyl amine protons during ligand synthesis. Dimethyl sulphoxide (DMSO) used as solvent was not $100 \%$ isotopically pure and contains some trace of DMSO- $\left(\mathrm{CH}_{3}\right)_{6}$ which gave a peak at $2.4983 \mathrm{ppm}$.

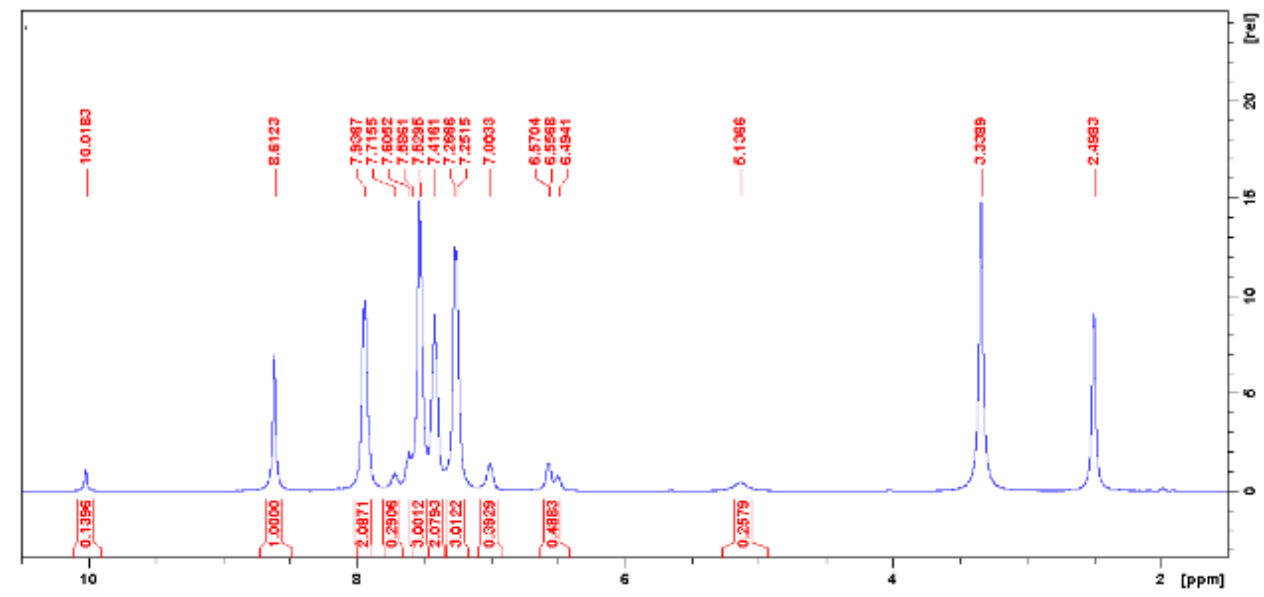

Figure3.2a. Proton $\left({ }^{1} H\right)$ NMR Spectra of Schiff Base-Nickel Complex

\subsubsection{Carbon $13\left({ }^{13} \mathrm{C}\right) \mathrm{NMR}$}

The ${ }^{13} \mathrm{C}$ spectra recorded on dimethyl sulphoxide (DMSO) in Figure $3.4 \mathrm{~b}$ showed a signal which appeared at $ð 193.670 \mathrm{ppm}$ and was assigned to the azomethine carbon atom $(\mathrm{CH}=\mathrm{N})$. The chemically nonequivalent aromatic ring carbon atom of the ligand furnished resonance peaks at chemical shift of 116.2032 , 126.4297, 129.1367, 129.2748, 129.6608, 129.9444, 131.9332, 135.0332, 136.4846, $136.6676,151.9367,161.1494 \mathrm{ppm}$ and quaternary carbon atoms which were parts of the rings and adjacent to the azomethine carbon and nitrogen as well, provided low intensity signals at $ð$ of 136.4846 and $151.9367 \mathrm{ppm}$. Trace of phenylamine droplets which were found in the ligand shows peaks at 114.4172, 121.4172, 121.4309 and $129.6170 \mathrm{ppm}$.

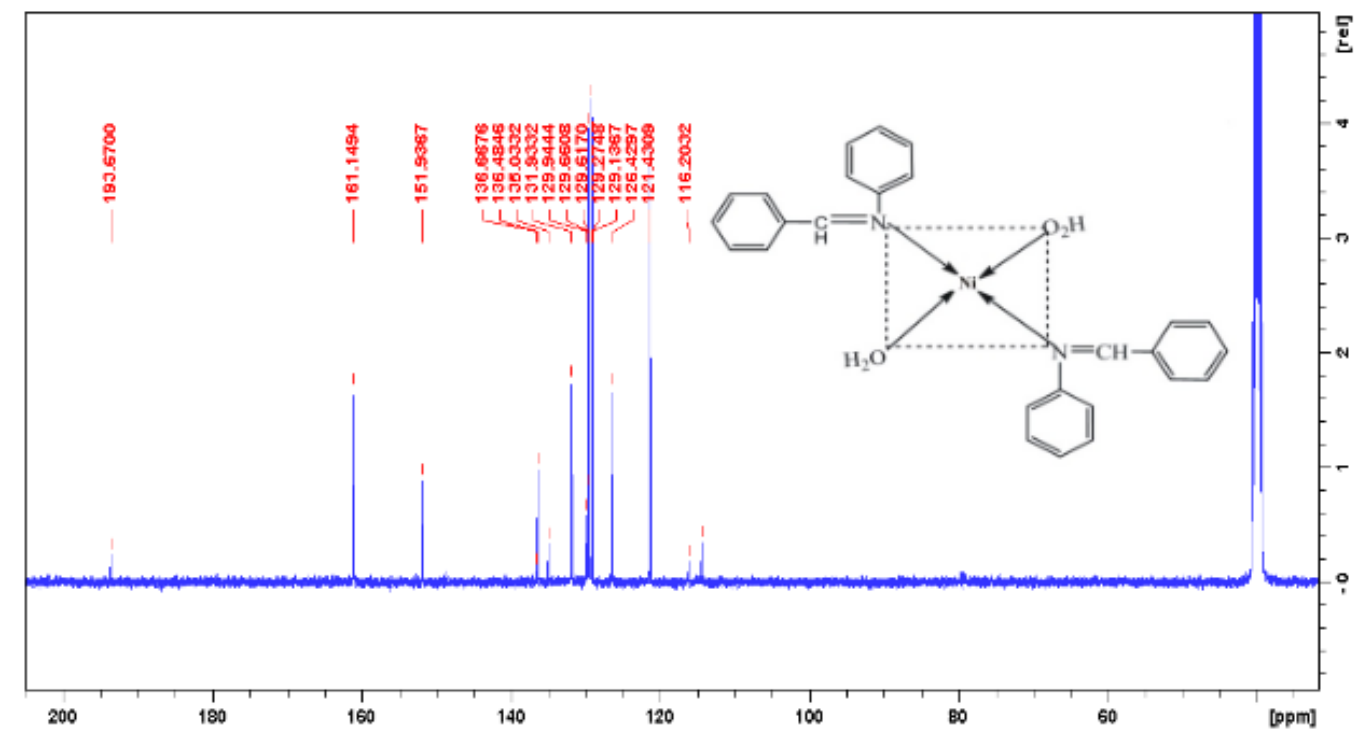

Figure3.2b. Carbon $\left({ }^{13}\right.$ C) NMR Spectra of Schiff Base-Nickel Complex 


\subsection{Interference Studies}

The effect of foreign ions on the absorbance of $4.0 \mathrm{ppm}$ nickel ion concentration is shown in Table 3.2. The criterion for interference was fixed at $\pm 0.5 \%$. That is, concentrations of foreign ions which cause relative deviations equal to, or lower than $5.0 \%$ were tolerated. Most of the ions tested were tolerated in a wide range of concentrations.

Some of the most tolerated ions are $\mathrm{Ag}^{+}, \mathrm{SO}_{4}{ }^{2-}, \mathrm{Cd}^{2+},\left(1.00 \times 10^{-1}\right.$ molL $\left.{ }^{-1} \mathrm{max}.\right)$ and least tolerated ions are $\mathrm{Ca},{ }^{+}, \mathrm{Zn}^{2+}, \mathrm{NO}_{3}^{-}, \mathrm{Cl}^{-}, \mathrm{CO}_{3}{ }^{2-}\left(5.00 \times 10^{-4} \mathrm{molL}^{-1} \max \right)$.

Table3.2. Effect of foreign ions on the absorbance of $4 \mathrm{ppm} \mathrm{Ni}^{2+}$

\begin{tabular}{|c|c|c|c|}
\hline Species & Added as & $\begin{array}{c}\text { Tolerated } \\
\text { conc. }\left(\text { molL }^{-1}\right)\end{array}$ & Relative deviation (\%) \\
\hline $\mathrm{Ca}^{2+}$ & $\mathrm{CaSO}_{4}$ & $5 \times 10^{-4}$ & 2.9 \\
\hline $\mathrm{Zn}^{2+}$ & $\mathrm{ZnCl}_{2}$ & $4.0 \times 100^{-2}$ & 2.5 \\
\hline $\mathrm{Cd}^{2+}, \mathrm{SO}_{4}{ }^{2-}$ & $\mathrm{CdSO}_{4} \cdot 6 \mathrm{H}_{2} \mathrm{O}$ & $1.4 \times 10^{-4}$ & -2.63 \\
\hline $\mathrm{Cu}^{2+}, \mathrm{Cl}^{-}$ & $\mathrm{CuCl}_{2}$ & $3.0 \times 10^{-2}$ & -2.91 \\
\hline $\mathrm{Ag}^{+}, \mathrm{NO}_{3}{ }^{2-}$ & $\mathrm{AgNO}_{3}$ & $1.0 \times 10^{-1}$ & -3.61 \\
\hline $\mathrm{K}^{+}, \mathrm{CO}_{3}{ }^{2-}$ & $\mathrm{K}_{2} \mathrm{CO}_{3}$ & $5 \times 10^{-4}$ & 3.7 \\
\hline
\end{tabular}

\section{CONCLUSION}

When a normal electronic structure of a substance is deformed there is either the production of the color (or) change of the color, thus when molecules containing one or more chromophores and auxochromes are subjected to irradiation, they undergo variation in electronic energy. Schiff bases play important roles in coordination chemistry as they easily form stable complexes with most transition metal ions and they are very efficient as ligands. The presence of the lone pair of electrons on the nitrogen atom of the imine bond means that they can be donated to the appropriated metal ion. The synthesized ligand and its Ni complex were characterized using nuclear magnetic resonance (NMR), melting point determination, electrical conductivity and infrared (IR) spectroscopic techniques.

\section{REFERENCES}

[1] Adams, R., Ballesteros-Garrido, R., Sacremento, F., Abaria, B., Ballesteros, R and Carmen Munoz, M. (2016). From Six-Coordinate to Eight-Coordinate Iron (II) Complexes with Pyridyltriazole-Pyrindine Framework. Journal of Coordination Chemistry. 18:7950-7954.

[2] Villar, A., Gorritxategi, E., Aranzabe, E., Fernandez, S., Otaduy, D and Fernandez, L.A. (2012). Low-cost Visible-near Infrared Sensor for on-line Monitoring of Fat and Fatty Acids Content During the Manufacturing Process of the Milk. Food Chemistry.135(4): 2756-2760.

[3] Aliyu, H.D. and Nwabueze, .J.N (2009). Complexes of Valerohydroxamic Acid and Isovalerohydroxamic Acid with Co(II), Ni(II), Cu(II) and Vo(IV). Journal of Chemical Society of Nigeria. 32(2):275-281.

[4] Skoog, D.A., Holler, F.J and Crouch, S.R. (2001). Principles of Instrumental Analysis (6th ed.). Belmont, CA: Thomson Brooks/Cole. pp.169-173.

[5] Loudon, G.M. (2002). Organic Chemistry $4^{\text {th }}$ Edn. Addison-Wiley California. P 150.

[6] Pam, A. A., Ato, R. S and Offem, J. O. (2013). Contribution of Automobile Mechanic Sites to Heavy Metals in Soil: A case study of North Bank Mechanic Village, Makurdi, Benue State, Central Nigeria. Journal of Chemical, Biological and Physical Sciences. 3(3) 2337-2347.

[7] Mamtani, R., Stern, P. and Cheema, S. (2011). Metals and Diseases: A Global Primary Health Care Perspective. Journal of Toxicology. 21: 1-11.

[8] Anand, P., Patil, V. M., Sharma, V. K, Khosa, R. L and Masand, N. (2012). Schiff bases: A Review on Biological Insights. International Journal of Drug Discovery 3(3): 851-68.

[9] Garima, Y and Jyoti, V. M. (2015). Green Synthesis of Schiff Bases by Using Natural Acid Catalysts. International Journal of Science and Research. 4(2): 121-127.

[10] Ibrahim, A. A and Omar, H. M (2013). Seasonal Variation of Heavy Metals Accumulation in Muscles of the African Cafish Clarias gariepinus and in River Nile Water and Sediments at Assiut Governorate, Egypt. Journal of Biology and Earth Sciences. 3(2): 236 - 248.

[11] Izah, C. F., Malomo, D., Okolo, P. O and Okuo, J. M. (2019). Novel Spectrochemical Determination of Cadmium Using 2-(benzylideneamino)ethanesulphonic acid. Journal of Chemical Society of Nigeria. 44(5): 754-771. 
[12] Gervasio, A. L., Ana, A. N., Daniel, B. M and Kerry, L. L. (2016). Heavy Metals; Cardiovacular Disease and the unexpected Benefits of Chelation Therapy. Journal of Am Coll. 67(20):2411-2418.

[13] Guo, W., Liv, H., Bacsa, J., Gao, Y., Lee, S and Hill, C. (2016). Syntheses, Structural Characterization and Catalytic Properties of Di and Tri nickel Polyoxometalates. Inorganic Chemistry. 55 (2): 461-466.

[14] Amit, R. Y., Vijaya, V. D., Gaurav, B. P. and Anand S. A. (2014) Synthesis, Characterization, Biological and Electrical Conductivity Studies of some Schiff Base Metal Complexes. Bulletin of Chemical Society of Ethiopia. 28(2): 255-264.

[15] Halli, M. B., Malipatil, R. S and Sumathi, R. B. (2012). Preparation and Pharacterization of Ni (II), Co (II), $\mathrm{Cu}$ (II), Cd (II), Zn (II) and Hg (II) Complexes with Schiff base Derived from Benzofuran-2-carbohydrazide and p-chloroacetophenone. Journal of Chemical, Pharmaceutical Research. 4(2):1259-65.

Citation: Emmanuel I. Chiedu, et.al, "Spectrophotometric Studies of N-Benzylideneaniline Ligand and its Nickel Complex", International Journal of Advanced Research in Chemical Science, 7(8), pp. 25-30. DOI: https:// doi.org/10.20431/2349-0403.0708003

Copyright: (C) 2020 Authors, this is an open-access article distributed under the terms of the Creative Commons Attribution License, which permits unrestricted use, distribution, and reproduction in any medium, provided the original author and source are credited. 